\title{
Insurance of the Termination Risk of Projects with Joint Companion Activity
}

\author{
Irina Sukhorukova* and Natal'ya Chistyakova
}

\author{
Department of Higher Mathematics, Plekhanov Russian University of Economics, Russian Federation
}

\begin{abstract}
Actuarial calculations are based on the study of mathematical models of financial schemes in insurance taking into account the stochastic nature of insurable events. They lie at the intersection of mathematical and economic disciplines. This paper is devoted to the formulation and investigation of the mathematical model of insurance of a joint project of partners from the risk of its early termination due to the retirement of one of the companions due to external circumstances. In case of an insured event, the partner remaining in the project receives insurance to continue the project. In order to assess the obligations of the insurance company, an economic-mathematical model of personal joint insurance of participants has been constructed to calculate the necessary characteristics of such an agreement. To describe the dynamically changing threats to terminate the insurance contract, the concepts of the intensity of retirement functions of insured persons are introduced, which are convenient in the study of insurance contracts with several participants. Possibilities of payment of insurance compensation to each partner are received and probability of that the insurance company should pay insurance compensation are received. Calculations are made using the example of specific functions of the intensity of retirement of partners. Practical recommendations are given related to the use of numerical methods or simulation methods in calculations based on the obtained universal formulas.
\end{abstract}

Keywords: Intensity of withdrawal, Insurance compensation, Distribution density, Distribution function, Economicmathematical model of risk insurance.

\section{INTRODUCTION}

One of the most popular types of insurance services in all developed countries is individual insurance. In Russia, the market of voluntary personal insurance is only beginning to develop. The state is interested in the accelerated development of this type of long-term insurance as it contributes to the receipt of additional funds in the economy of the country and serves as a source of increasing the investment attractiveness of the country and the welfare of all citizens (Falin 1996). At the same time, there are a number of negative objective factors that limit the growth of this type of insurance for citizens and legal entities.

First of all, this restriction is due to the presence of high inflation in the Russian Federation, but now the Central Bank of Russia is doing everything possible to keep inflation at around 4\%. A low level of inflation is considered a priority for the development of the voluntary insurance market. Low solvency of the general population restrains the long-term insurance in Russia. The acquisition of a life insurance policy with a low level of income is devoid of any economic sense, since the size of the available benefits will be insignificant and money will be withdrawn from the economic turnover for a long-term period. The appearance of a significant number of citizens with

*Address correspondence to this author at the Department of Higher Mathematics, Plekhanov Russian University of Economics, Russian Federation; Tel: (499) 2370530; Fax: (499) 2370530;

E-mail: suhorukovaira@yandex.ru medium and high incomes, on the contrary, increases the attractiveness of the life insurance.

Another constraining factor is a rather weak development of the fund market in Russia. Practically, at the moment there are no long-term instruments that allow to effectively allocate long-term reserves of insurance companies, working under the individual life insurance program. Also, there are no legislative tax incentives for insurers for life insurance (Zhuravlyova 2016). The current practice of life insurance taxation is undoubtedly a slowing factor in the development of this insurance industry.

However, the recently adopted tax code of the Russian Federation provides for the availability of income tax benefits when receiving payments under the life insurance contract if the insurance period is more than five years and there are no payments in the first year of the insurance. Another significant impediment to the development of the individual life insurance market is the double taxation of incomes received by individuals (Kulikova, et al. 2016). For the first time, income tax deduction occurs when the employer pays an insurance prize for each of its employees, while for the employees themselves as individuals, payment of the insurance tariff at their own expense does not reduce the taxable base of the income tax. For the second time it is the withholding of the tax on the payment of insurance compensation in favor of the insured person. However, the most significant factor slowing the development of the 
personal insurance market is the lack of motivated demand among the population of our country in this type of insurance.

Insurance companies do not conduct an active advertising company of such types of insurance and do not represent competitive attractive insurance products. The population itself cannot adequately assess its financial capabilities and assess the prospects of meeting its needs with the help of benefits provided by insurance products within the insurance program. There is also such a deterrent among the population, as mistrust to the insurance industry in general and insurance companies (Zolotareva 2016). Life insurance refers to long-term insurance products, the policy is purchased for a period of not less than five years, in the future for twenty years, but there is no certainty that the insurance company will operate during this period, it will not be revoked a license and it will not disappear anywhere.

In conditions of economic instability, it is difficult to ensure citizens' confidence in insurance companies. The majority of the population has no information at all about the existence of a personal insurance program (Brusov and Filatova, 2016). The voluntary personal insurance program is not in demand and even those citizens who heard about its existence, can not clearly imagine what differences in insurance products are and how insurance tariffs are formed. In the insurance companies themselves there is a shortage of qualified consultants, financial specialists who possess professional knowledge and skills, able to explain the benefits of the life insurance program and contribute to the development of the insurance market in accordance with international standards. Only a joint program of the state and insurance companies will eliminate existing obstacles to market development personal insurance. The observed gradual increase in citizens' income raises interest in their own lives and the lives of close people; this circumstance contributes to an increase in interest in the long-term insurance products. The state needs to strengthen supervision over the activities of insurance companies in order to improve the guarantees of the insurer's performance of the terms of the personal insurance contract. To implement these goals, a law on actuarial activity was adopted.

\section{MATERIALS AND METHODS}

Actuarial calculations, based on the principle of obligations equality of the insurer and the insured person, allow finding the share of each insurer's participation in the creation of the insurance fund, i.e. determine the size of tariff rates, the impact of macroeconomic indicators on the size of the insurance premium . To determine the amount, to be paid to each of the insurers in the general insurance fund, it is first necessary to calculate the amount of financial liabilities of the insurer, or the amount of future payments under insurance contracts. These problems are widely represented in the studies of foreign authors (Bowers, et al., 1997; Gantenbein and Mata, 2008; Panjer, et al., 1998; Kaas, et al., 2001).

The insurer must have information about how many objects will suffer or will not suffer from the insurance event in order to determine the sufficient level of the insurance fund. Based on the statistics on actuarial techniques, you can calculate the amounts of future payments. For example, having information about the mortality of the population, it is possible to calculate the probability of survival and death for people of different ages (Actuaries: Problems, Information, Events). Based on these data, mortality tables are constructed that show the change in the dynamics of the number of people of a certain age category. Using the mortality tables of the population, net rates for various types of personal insurance and for the payment of pension for a certain age category of individuals are calculated. Taking into consideration the long-term nature of these investments, tariff rates are initially reduced by the amount of income received in the form of the loan interest on the insurer's funds used as credit resources.

Actuarial calculations are also used for the economic justification for the creation of a reserve fund of an insurance company for each personal insurance contract. In addition, actuarial calculations allow determining the amount of redeemed reduced sums of insurance, which makes it possible to recalculate insurance premiums when changing the terms of life insurance contracts.

To analyze the problem posed, as well as to find the best ways to solve it, it is proposed to use the economic model of optimizing the management of the insurance business using computer modeling, the successful application of which was considered, for example, in (Sukhorukova and Chistyakova, 2018, p. 195-203; Sukhorukova and Chistyakova, 2018, p. 847857). One of the main tasks in this case is to find an effective mechanism to reduce costs and increase the profit of the insurance company. 
As development of the methodology of actuarial calculations, this article deals with the statement of the problem associated with insurance of risks in the implementation of joint activities of two partners. It is assumed that each partner has an obligation to fulfill its share in the project for a certain period of time. Let's consider the task of insuring the risk of withdrawal of one of the partners due to external circumstances. Namely, in the event of withdrawing of a partner from the project for external reasons before the completion of his obligations, the insurance company pays the remaining amount of the insurance sum specified in the contract to compensate for the loss and restoration of the project. Let's find the probability of paying insurance compensation to each of the partners.

\section{RESULTS AND DISCUSSION}

We introduced the values, necessary for the calculation. The moment of conclusion of the contract is considered to coincide with the beginning of the project. In our problem it will be a zero time point. We denoted through $T_{1}$ and $T_{2}$ the time intervals of the project obligations of the first and second partners, respectively. The apriori time of the project validity (Sukhorukova and Chistyakova, 2018, p. 146-151) obviously covers the interval $\left(0, \max \left\{T_{1}, T_{2}\right\}\right)$. Because the individual withdrawal from the project is possible due to external circumstances, the duration of each partner's work within the project is a random variable. Therefore, we consider the random variables $\tau_{1}$ and $\tau_{2}$ the real time of participation of the first and second partners, respectively. By condition, compensation is paid in the event of withdrawing from the project of the partner before the completion of the obligations assumed by him, that is, on a time interval of joint work of the partners $\left(0, \min \left\{T_{1}, T_{2}\right\}\right)$. The same time interval is the apriori term of the insurance contract. Suppose that the initial data are given by: a vector of parameters $\left(T_{1}, T_{2}\right)$ as well as the intensity of withdrawal of partners $u_{x}$ and $\tilde{\mu}_{y}$, depending on the current length of service in the project $x \in\left(0, T_{1}\right), Y \in\left(0, T_{2}\right)$ and characterizing external threats to the partners. Let us concretize these terms and give a definition of each of the quantities introduced.

We call the intensity of withdrawal at the time $x$ of the first partner the function

$\mu_{x}=\lim _{\Delta \rightarrow 0+} \frac{1}{\Delta} P\left(\tau_{1}<x+\Delta \mid \tau_{1}>x\right), 0<x<T_{1}$.

Similarly, intensity of withdrawal at the moment $y$ of the second partner is the following $\tilde{\mu}_{y}=\lim _{\Delta \rightarrow 0+} \frac{1}{\Delta} P\left(\tau_{2}<y+\Delta \mid \tau_{2}>y\right), 0<y<T_{2}$

Denoting the distribution function of a random variable $\tau_{1}$ through $F_{\tau_{1}}(x)$, and its survival function: $S_{\tau_{1}}(x)=1-F_{\tau_{1}}(x)=P\left(\tau_{1}>x\right)$, we receive,

$$
\begin{aligned}
& \mu_{x}=\lim _{\Delta \rightarrow 0+} \frac{1}{\Delta} P\left(\tau_{1}<x+\Delta \mid \tau_{1}>x\right)= \\
& =\lim _{\Delta \rightarrow 0+} \frac{F_{\tau_{1}}(x+\Delta)-F_{\tau_{1}}(x)}{\Delta * P\left(\tau_{1}>x\right)}=\frac{F_{\tau_{1}}{ }^{\prime}(x)}{S_{\tau_{1}}(x)}=\frac{-S_{\tau_{1}}{ }^{\prime}(x)}{S_{\tau_{1}}(x)}
\end{aligned}
$$

The differential equation is obtained $\mu_{x}=\frac{-S_{\tau_{1}}{ }^{\prime}(x)}{S_{\tau_{1}}(x)}$ (Zhmurko, et al., 1997). Let us now find the solution of the given differential equation. We have: $d \ln S_{\tau_{1}}(x)=\mu_{x} d x$

$\Rightarrow \ln S_{\tau_{1}}(t)-\ln S_{\tau_{1}}(0)=\int_{0}^{t}-\mu_{x} d x \Rightarrow$

$\Rightarrow \ln S_{\tau_{1}}(t)=-\int_{0}^{t} \mu_{x} d x \Rightarrow S_{\tau_{1}}(t)=e^{-\int_{0}^{t} \mu_{x} d x}$

Here we used the obvious equality, $\ln S_{\tau_{1}}(0)=0$

Using the rule of differentiating the integral over the variable upper limit, we finally obtain that the partial densities of the distribution of random variables $\tau_{1}$ and $\tau_{2}$ are as follows:

$f_{\tau_{1}}(t)=F_{\tau_{1}}{ }^{\prime}(t)=-S_{\tau_{1}}{ }^{\prime}(t)=\mu_{t} S_{\tau_{1}}(t)=$

$=\mu_{t} e^{-\int_{0}^{t} \mu_{x} d x}, \quad t<T_{1}$,

$f_{\tau_{2}}(s)=\tilde{\mu}_{s} e^{-\int_{0}^{s} \mu_{d} d y}, \quad S<T_{2}$.

Let us return to the statement of the problem. In the framework of this article, we believe that the withdrawal of a companion is due to external reasons, i.e. random variables $\tau_{1}$ and $\tau_{2}$ are independent. Then, because of equity (1), the density of the joint distribution of a random vector $\left(\tau_{1}, \tau_{2}\right)$ has the following form:

$$
\begin{aligned}
& f_{\left(\tau_{1}, \tau_{2}\right)}(t, s)=f_{\tau_{1}}(t) f_{\tau_{2}}(s)=\mu_{t} e^{-\int_{0}^{t} \mu_{x} d x} . \\
& . \tilde{\mu}_{s} e^{-\int_{0}^{s} \mu_{s} d y}, 0<t<T_{1}, 0<S<T_{2}
\end{aligned}
$$

By condition, compensation is paid in the event of withdrawing from the project of the partner before the completion of the obligations assumed by him, that is, in the time interval of joint work of the partners $\left(0, \min \left\{T_{1}, T_{2}\right\}\right)$. To implement this insurance event, it is 
necessary and sufficient that one of two mutually exclusive events occur: either the first partner left the project on a time interval of joint work, not having completed his obligations, and the second one will receive compensation, that is $\left\{\tau_{1}<\min \left\{T_{1}, T_{2}\right\} \cap \tau_{2}>\tau_{1}\right\}$; or, on the contrary, the second companion left the project on a time interval of joint work, and the former will receive compensation, that is $\left\{\tau_{2}<\min \left\{T_{1}, T_{2}\right\} \cap \tau_{1}>\tau_{2}\right\}$.. When calculating the probabilities of each of these events, two different areas arise, depending on the inequality between the terms of the partners' obligations $T_{1}$ and $T_{2}$. Figures 1 ,

2 show shaded regions of values $\left(\tau_{1}, \tau_{2}\right)$, corresponding to the insured event with withdrawal of the first partner, and in Figures 3, 4 the areas corresponding to the insured event with withdrawal of the second partner. On the axes, in addition to the values of the random variables $\left(\tau_{1}, \tau_{2}\right)$ designations of their current values are mentioned $(t, s)$, necessary for further calculation of the integrals.

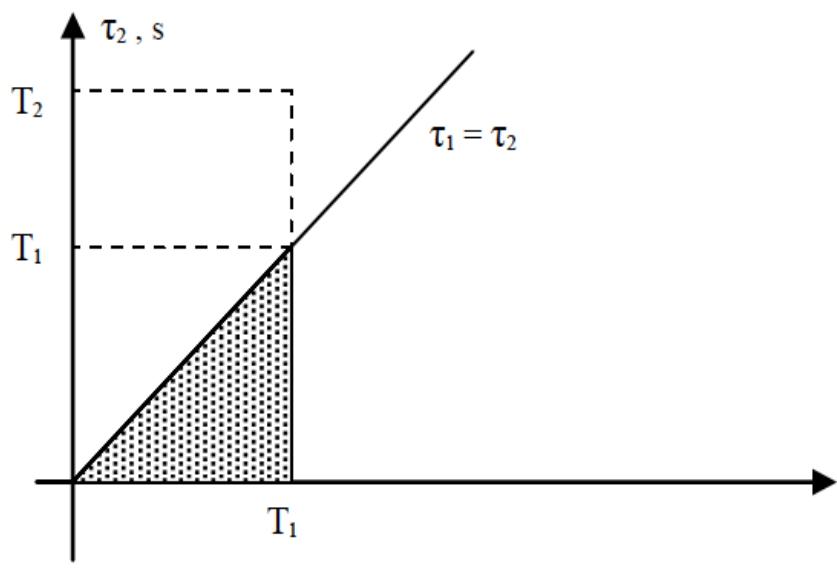

Figure 1: Shaded regions of values $\left(\tau_{1}, \tau_{2}\right)$, corresponding to the insured event with withdrawal of the first partner.

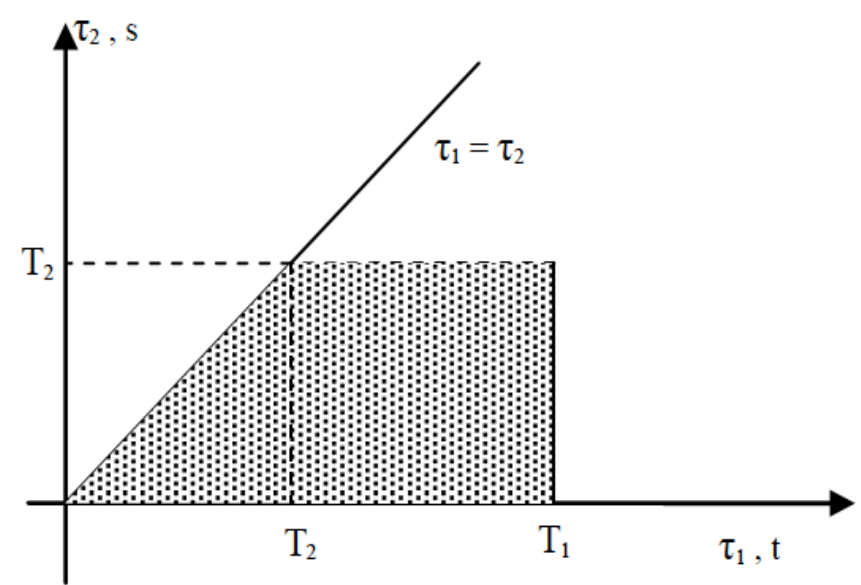

Figure 2: Shaded regions of values $\left(\tau_{1}, \tau_{2}\right)$, corresponding to the insured event with withdrawal of the first partner.

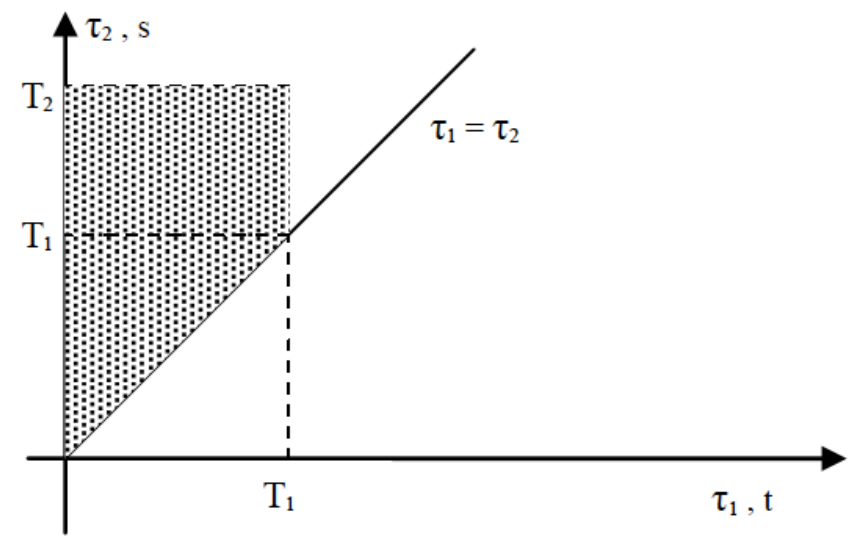

Figure 3: The areas corresponding to the insured event with withdrawal of the second partner.

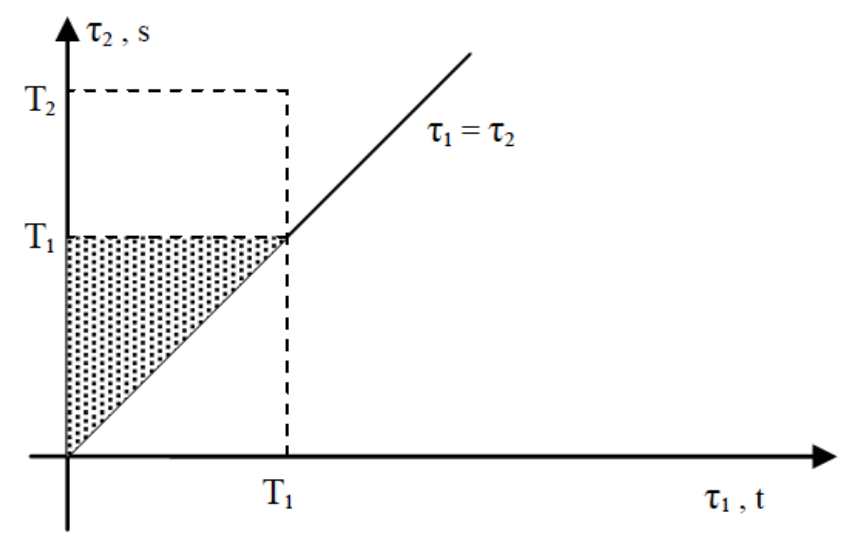

Figure 4: The areas corresponding to the insured event with withdrawal of the second partner.

Using formula (2) for the density of the joint distribution of a random vector $\left(\tau_{1}, \tau_{2}\right)$, we will receive the probabilities of payment of the insurance amount due to the early withdrawal from the project by the first (or second) partner, respectively:

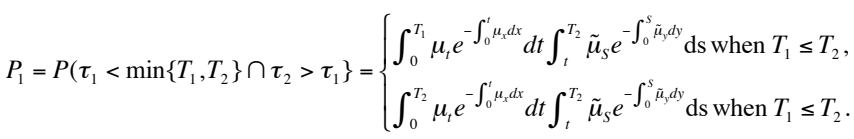

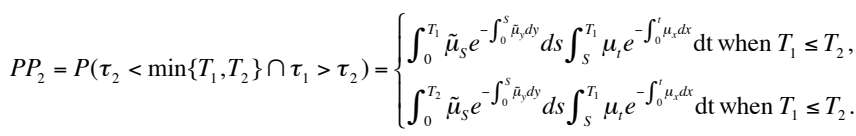

The aggregate obligations of the insurance company to both partners to secure such an agreement come with a probability $P_{1}+P_{2}$ which is the following:

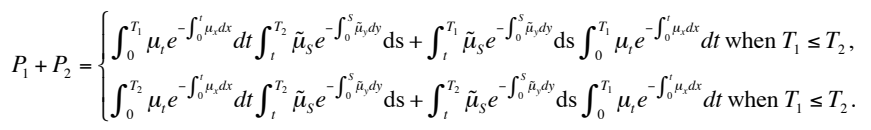

For a numerical implementation of the algorithm for calculating the probabilities, we give a purely illustrative 
example of specific calculations. Suppose that the intensity of withdrawal from a joint project for external reasons of the first partner at the time $x$ the project operation has the form of $\mu_{x}=\frac{1}{T_{1-x}}, x \in\left(0, T_{1}\right)$, and the similar intensity of withdrawal of the second partner has (Katsnel'son, et al., 1995) a mirror form $\tilde{\mu}_{x}=\frac{1}{T_{2-x}}, x \in\left(0, T_{2}\right)$. Let us calculate the probability (3): the first partner left the project without completing his obligations, and the second will receive compensation. After substituting the intensity of withdrawal, the probability becomes:

$$
\begin{aligned}
& P_{1}=\left\{\begin{array}{l}
\int_{0}^{T_{1}} \frac{1}{T_{1}-t} e^{-\int_{0}^{t} \frac{1}{T_{1}-x} d x} d t \int_{t}^{T_{2}} \frac{1}{T_{2}-s} e^{-\int_{0}^{s} \frac{1}{T_{2}-y} d y} d s, \text { when } T_{1} \leq T_{2}, \\
\int_{0}^{T_{2}} \frac{1}{T_{1}-t} e^{-\int_{0}^{t} \frac{1}{T_{1}-x} d x} d t \int_{t}^{T_{2}} \frac{1}{T_{2}-s} e^{-\int_{0}^{s} \frac{1}{T_{2}-y} d y} d s, \text { when } T_{1} \geq T_{2} .
\end{array}\right. \\
& =\left\{\begin{array}{l}
\int_{0}^{T_{1}} \frac{1}{T_{1}-t} e^{-\int_{0}^{t} \frac{1}{T_{1}-x} d x} d t \int_{t}^{T_{2}} \frac{1}{T_{2}-s} e^{\ln \frac{T_{2}-s}{T_{2}}} d s=\int_{0}^{T_{1}} \frac{1}{T_{1}-t} e^{-\int_{0}^{t} \frac{1}{T_{1}-x} d x} \cdot \frac{1}{T_{2}}\left(T_{2}-t\right) d t, \text { when } T_{1} \leq T_{2}, \\
\int_{0}^{T_{2}} \frac{1}{T_{1}-t} e^{-\int_{0}^{t} \frac{1}{T_{1}-x} d x} d t \int_{t}^{T_{2}} \frac{1}{T_{2}-s} e^{\ln \frac{T_{2}-s}{T_{2}}} d s=\int_{0}^{T_{2}} \frac{1}{T_{1}-t} e^{-\int_{0}^{t} \frac{1}{T_{1}-x} d x} \cdot \frac{1}{T_{2}}\left(T_{2}-t\right) d t, \text { when } T_{1} \geq T_{2} .
\end{array}\right.
\end{aligned}
$$

Further, by analogy, carrying out integration in the remaining expression, we obtain:

$$
P_{1}=\left\{\begin{array}{l}
\int_{0}^{T_{1}} \frac{1}{T_{1}-t} * \frac{T_{1}-t}{T_{1}} * \frac{1}{T_{2}}\left(T_{2}-t\right) d t=\frac{1}{T_{1} T_{2}}\left(T_{1} T_{2}-\frac{T_{1}^{2}}{2}\right)=1-\frac{T_{1}}{2 T_{2}}, \quad \text { when } T_{1} \leq T_{2}, \\
\int_{0}^{T_{2}} \frac{1}{T_{1}-t} * \frac{T_{1}-t}{T_{1}} * \frac{1}{T_{2}}\left(T_{2}-t\right) d t=\frac{1}{T_{1} T_{2}}\left(T_{2}^{2}-\frac{T_{2}^{2}}{2}\right)=\frac{T_{2}}{2 T_{2}}, \quad \text { when } T_{1} \leq T_{2} .
\end{array}\right.
$$

Similarly, we obtain an expression for the probability (4), when the second partner left the project without completing his obligations, and the former will receive compensation.

$$
P_{1}=\left\{\begin{array}{l}
\frac{T_{1}}{2 T_{2}} \text { when } T_{1} \leq T_{2}, \\
1-\frac{T_{2}}{2 T_{1}} \text { when } T_{1} \geq T_{2} .
\end{array}\right.
$$

The aggregate obligations of the insurance company to both partners to secure such an agreement come with the probability

$$
P_{1}+P_{2}=\left\{\begin{array}{l}
1-\frac{T_{1}}{2 T_{2}}+\frac{T_{1}}{2 T_{2}}=1 \text { when } T_{1} \leq T_{2}, \\
1-\frac{T_{2}}{2 T_{1}}+\frac{T_{2}}{2 T_{1}}=1 \text { when } T_{1} \geq T_{2} .
\end{array}\right.
$$

This result is logical, since the corresponding intensity of threats is taken, but it served as a convenient illustration of calculations and at the same time allowed us to verify the formulas.

\section{CONCLUSIONS}

Thus, it is naturally to assume that in general practical numerical forecasting of the compensation payment probability by the insurance company may proceed successfully through careful selection of probabilistic characteristics describing external threats for partners. This can be achieved by accumulation of relevant statistics by leading insurance companies, which offer this insurance product, and by use of numerical methods and methods of simulation. In the presented research work, the theoretical basis for solving the problem of assessing the risk of terminating a joint project of several participants due to the early retirement of one of the project participants is proposed. The completed scientific and methodological substantiation and the developed actuarial insurance model of a joint project involving several participants from the risk of early termination due to the retirement of one of the partners due to external circumstances contributes to the objective assignment of insurance payments, is the basis for the stable operation of the insurance company in the mutual insurance services market responsibility. Allows you to evaluate, in case of withdrawal from the project partner before the completion of its obligations, the insurance company payment to the insurance company remaining in the project partner specified in the contract in order to compensate for the loss and restore the project. Mathematically calculated the probability of payment of insurance compensation to each of the participants of a joint project and the probability of the total obligations of the insurance company to both partners to secure such a contract.

\section{REFERENCES}

Actuaries: Problems, Information, Events. Information website, http://www.actuaries.ru

Bowers N.L., Gerber H.U., Hickman J.C., Jones D.F., Nesbitt S.J., "Actuarial Mathematics", 2nd ed., Schaumburg, IL: The Society of Actuaries, 1997, $730 \mathrm{p}$.

Brusov P.N., Filatova T.V. Investment models with uniform debt repayment and their applications. Journal of Mathematical Sciences. 2016. T. 216. № 5. C. 627-632.

Falin G.I., "Mathematical foundations of the theory of life insurance and pension schemes", Moscow: Edition of Moscow State University, 1996, 221 p. (in Russ.)

Gantenbein M., Mata M. A., "Asset Protection Through Swiss Annuities and Life Insurance: View from the United States", In Swiss Annuities and Life Insurance: Secure Returns, Asset Protection, and Privacy, 2008. https://doi.org/10.1002/9781119198130.ch7

Kaas R., Goovaerts M., Dhaene J., Denuit M., "Modern Actuarial Risk Theory", Dordrecht: Springer Netherlands, Kluwer Academic Publishers, 2001, 381 p.

Katsnel'son, A.A., Sukhorukova, I.V., Revkevich, G.P., Olemskoi, A.I. (1995), Self-Oscillation Processes During the Structure 
Relaxation of Palladium-Metal Alloys (pd-w) Saturated with Hydrogen. Physics-Uspekhi. 1995. T. 38. № 3. C. 317-323.

Kulikova L.I., Semenikhina N.B., Vetoshkina E.Y. Aplication of acturial calculations when bulding a report on companys financial position. Academy of Marketing Studies Journal. 2016. T. 20. № Special Issue. C. 96-102.

Panjer H.H., Boyle P.P., Cox S.H., Dufresne D., Gerber H.U., Mueller H.H., Pedersen H.W., Pliska S.R., Sherri M.S., Shiu E.S.W., Ken Seng Tan (eds), "Financial Economics: with Applications to Investments, Insurance and Pensions", Schaumburg, IL: The Society of Actuaries, 1998, $546 \mathrm{p}$.

Sukhorukova I.V. Chistyakova N.A., "Methodical Aspects of Actuarial Mathematics Teaching, Astra Salvensis VI (2018), Special Issue p. 847-857.

Sukhorukova I.V., Chistyakova N.A. "Economic regulation and mathematical modeling of insurance product cost", Regional Science Inquiry, Vol. X, (2), 2018, pp.195-203
Sukhorukova I.V., Chistyakova N.A. "Optimization of the Formation of the Capital Structure of the Insurance Company, Taking into Account the National Specifics of Insurance", Journal of Reviews on Global Economics, 2018, 7, pp. 146-151. https://doi.org/10.6000/1929-7092.2018.07.12

Zhmurko, G.P., Kuznetsova, V.N., Katsnelson, A.A., Portnov, V.K., Sukhorukova, I.V. (1997) An experimental rejoining of the. Pt-W phase diagram. Vestnik Moskovskogo Universiteta Seriya 2. Chemistry. 1997. T. 38. № 2. C. 126.

Zhuravlyova N.M. Possibilites of the use of actuarial calculations are in economic activity Knowledge. 2016. № 8-2 (37). C. 92-96.

Zolotareva V.P., "The role of insurance in accelerating the investment processes in post-reform Russia", Journal of Russian Entrepreneurship, Vol. 17, No. 7, 2016, pp. 919-930 (in Russ.)

Received on 03-09-2018 Accepted on 16-02-2019

Published on 12-03-2019

DOI: https://doi.org/10.6000/1929-7092.2019.08.23

(C) 2019 Sukhorukova and Chistyakova; Licensee Lifescience Global.

This is an open access article licensed under the terms of the Creative Commons Attribution Non-Commercial License (http://creativecommons.org/licenses/by-nc/3.0/) which permits unrestricted, non-commercial use, distribution and reproduction in any medium, provided the work is properly cited. 